\title{
Aligning IT With Business Objectives: A Critical Survival And Success Factor In Today's Business
}

Ahmed Elmorshidy, Ph.D., Claremont Graduate University, USA / Gulf University for Science \& Technology, Mishref, Kuwait

\begin{abstract}
Alignment of IT with business objectives is a critically important topic in academic and industry. It is the key of success for modern organizations that is needed to survive and compete. It refers to the degree of congruence between business and IT strategies. This paper discusses the importance of aligning IT with business objective and the different effective strategies to align IT with business objectives. The paper also reviews the current research moles developed in support of this important concept. The paper further introduces a new theoretical framework for aligning IT with business objectives that analyze and integrate leading research models in this area combined with the well-established information systems success model of Mclean and DeLone.
\end{abstract}

Keywords: IT Strategies; Business Objectives; Business Success; Critical Survival Factor

\section{INTRODUCTION}

n today's turbulent and competitive business environment, survival not even success has become a major challenge. The basic foundation strategy that any type of business should follow is to align Information system to exactly achieve these goals. The company can build a state of the art IT system or a website that cost a fortune, but if this system is not representative of the original business goals, it will not be effective if not completely useless. Baina et al. (2008) stated that "Interoperability of enterprise systems can be seen as the operational aspect of a larger enterprise concern: Organization Alignment". During several years, information technologies have been seen as a technological means to implement business objectives. However, information and communication technologies growth implies creation of dedicated teams and departments working exclusively on the lead of IT projects inside the enterprise. (Baina et al. 2008). IT strategy intends to contribute positively to the creation of new business strategies or better support existing business strategy. This aim is often ensured by prospecting types and range of IT systems and capabilities potentially available to the organization. Linking business and IT more tightly offers many benefits, including improved decision-making and corporate agility. In current times, IT plays an important role in implementing the strategic plans of the companies. It has become vital for the organizations to provide the services in improved and efficient way. Business strategy and IT strategy should work in uniformity for the business user to understand the enterprises' system alignment with business information integration. (Sarhandiet al. 2011). IT and IS are very important in the processes of business planning, design, analysis, operations management, and strategic decision making. Alignment is described as the appropriate and timely application of IT, in harmony with business objective, strategies, and requirements. Business and IT alignment occurs when the respective strategies are interwoven in such a way that the right things are done. And things are done right, to deliver greater value to the organization. This implies that successful alignment is a twoway relationship, a give and take between IT and business. (Infosys 2012)

Strategic alignment of IT with business means that the objective of the IT department of a company should be set in line with the company objectives. Business-IT alignment refers to applying Information Technology (IT) in an appropriate and timely way, in harmony with business strategies, goals and needs. (Sarhandiet al. 2011) 


\section{HOW TO ALIGN IT WITH BUSINESS OBJECTIVES?}

Any business-IT alignment model or strategy must ultimately pursue one goal—continually optimize returns to the business from IT investments, including investments in projects, capital, service, support, maintenance, and any other IT effort or expenditure. The key success factor for aligning IT spending and efforts with business needs is mutual leadership and accountability. Business leaders must lead IT and CIOs must become business leaders. CIOs certainly need to increase their own accountability for IT results, but they must also help hold the business accountable for IT as well. (Growthwave 2010)

Regardless of its role, every IT activity, project, or service must play a part in creating business value. Also, an IT agenda must work must work towards achieving business-related and not IT-related metrics in order to improve alignment. Furthermore, businesses should be aware of their IT resources, which is something they often neglect to do. This is important because their business' competitiveness depends a lot on the quality of their technology resources and whether these resources nimble or efficient enough to meet changing market needs.

According to Haydamack and Johnson (2008), integrating the strategic planning process into the Intel IT Management Systems, the overarching activities used to manage the organization (planning, decision making, and evaluation activities) flow naturally from one step to the next. The two- to five-year plan is communicated throughout IT to provide an understanding of our environment and enlist support for the strategic directions.

The Intel strategy aimed at integrating the strategic planning calendar with the Intel corporate planning cycle, keeping Intel IT activities synchronized with the company's direction. It consolidates expertise and ideas from across Intel IT, bringing together a variety of perspectives in an efficient manner. Responds to changes in the industry by evaluating and adjusting the plan on a regular basis, helping to ensure it is always up to date.

According t o Lochan and Shah (2010), a survey of more than 500 senior executives found that despite devoting enormous resources and energy trying to align IT investments with their most important business needs, fewer than one in five felt their efforts were succeeding. Trouble typically starts when business units hand off their strategy to IT at too high a level. The broad goals are not concrete enough to be converted into well-informed IT decisions. In response, the proposals IT develops are defined at too low a level—often as a one-year operating plan rather than a comprehensive program to reach a strategic destination. Effective alignment can occur only when IT and business strategy are anchored in clearly articulated business capabilities. Capabilities are the specific skills needed to achieve competitive leadership. They are dynamic and give the organization an ability to adapt to changing market conditions. Supporting business capabilities permits IT to respond flexibly to essential business needs.

Leading companies follow a five-step process for unlocking IT's full potential to deliver business value: 1 . Define business imperatives and the capabilities that underpin them, 2. Identify IT capabilities that support business capabilities and plug gaps, 3. Design the operations and technology architecture. Rather than develop IT features on demand, managers need to establish principles to guide IT architecture and the way new features are built and operated, 4. Develop the IT-strategy roadmap. Aligning IT with business objectives requires a commitment and a roadmap. Managers must identify key IT investment needs that will close the alignment gaps, then group them into IT investment themes, and 5. Reallocate IT spending as business priorities evolve. Periodically, companies need to re-apply a business lens to IT costs to ensure alignment.

According to Strassmann (1998), the following are critical success factors for aligning IT with business goals: 1. Alignment Must Show Enhancements to a Business Plan, 2. Alignment Must Remain Updated as the Business Evolves, 3. Alignment Must Overcome Obstacles to its Purposes, 4. Alignment Must Overcome Obstacles to its Purposes The original project plan requires documented agreements of any changes to keep it current. It should not gather dust in files, until recovered by auditors after a project is ready for autopsy and 4. Alignment Must Relate to Benefits. To achieve alignment, one must first identify the sources of misalignment. If profitability or performance does not meet expectations, there must be denumerable reasons why this is so. 
Fenwick (2012) advised to think beyond alignment and create a business strategy based on technology. In order to do that, he suggested a framework that involves several steps: 1. Tackle Goals and Objectives First, 2. Model Business Differentiators, 3. Feed Strategy Discussions With Data-Driven Insights, 4. Develop Multiple Business Technology Strategies, 5. Develop a Living Technology Road Map, 6. Create IT To Support The Business Strategic Plans.

\section{REVIEW OF CURRENT IT/BUSINESS ALIGNMENT MODELS}

The evolution of IT resources and competencies is one of the main driving forces for efficiency and economic success of organizations. Venkatraman et al. (1999) define four interaction perspectives between IT and Business activities at the strategic level as depicted in Figure 1.

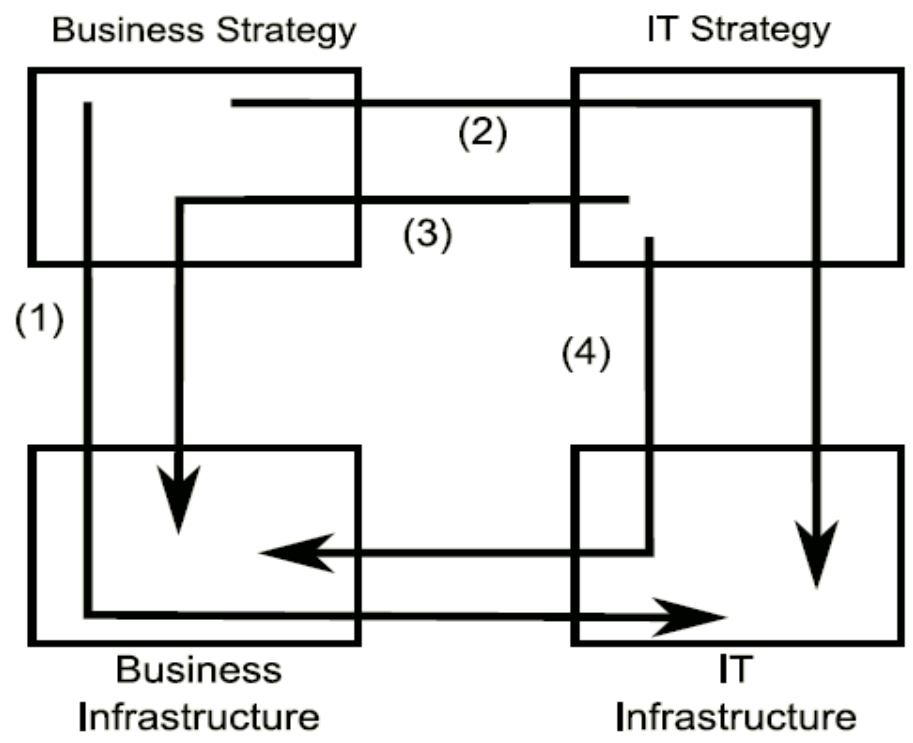

Figure 1. Strategic Alignment Model (Venktraman Et Al. 1999)

The strategy component corresponds to the classical, hierarchical view of strategic management. It considers the business strategy as the driver of both organization design choices and the logic of the IT infrastructure. Top Management formulates the strategy; IT Management is only considered as strategy implementer. The technology perspective also views the business strategy as the driver. However it involves the formulation of an IT strategy to support the chosen business strategy and the corresponding specification of the required IT infrastructure and processes. The top management should provide the technology vision to articulate the logic and choices pertaining to IT strategy that would best support the chosen business strategy. The competitive perspective is concerned with the exploitation of emerging IT capabilities to: impact new products and services, influence the key attributes of strategy, as well as develop new forms of relationships. Finally, the service level perspective focuses on how to build world class IT organization.. In this perspective, the role of business strategy is indirect. This perspective is often viewed as being necessary, but not being sufficient, to ensure the effective use of IT resources and to be responsive to the growing and fast changing demands of the end-user population.

Since few years it is known that business organizations are expanding vividly in the areas where IT is used for aligning with business strategies. So, therefore, IT creates value for firm through creativity and implementation of sound infrastructural services. This helps to exploit business opportunities, which include the use of business innovation through dynamic re-configuration and quick response to business environment issues. Alignment of business and IT enhances coordination, customer satisfaction and product development.

Figure 2 represents the Strategic Alignment Maturity“(SAM) by (Jerry Luftman 2000 and Luftman \& Brier 1999). The approach applied to attain and sustain business-IT alignment focuses on understanding the alignment 
maturity, and on maximizing alignment enablers and minimizing inhibitors. The process includes the following six steps "Set the goals and establish a team, Understand the business-IT linkage, Analyze and prioritize gaps, Specify the actions (project management), Choose and evaluate success criteria, Sustain alignment" (Luftman \& Brier, 1999). In addition (Luftman, 2000), talks more how on organization can make use of the "SAM" model for assessing and evaluating all related business activities by integrating them with business-IT alignment maturity for common organizational improvement. They include the following six steps, below diagram. From steps one to five which the level of alignment maturity level, while the 5th one showing the higher level of maturity alignment processes. However, the six steps of IT business alignment maturity criteria is based on how organizational executive or individual can understand and perform the require tasks to enable or bring improvement in regard to every objective that will align the level of business-IT alignment maturity to an organization. Which at the long-run the appropriate integration of IT and business executive decisions will reflect and determined through a successful evaluation of the criteria, will be based on how each of the steps or criteria of implemented. (Luftman, et al., 2004) argued that effectiveness of the linkages relating IT and business domains are critically important to sustaining competitive advantage in today's hyper-competitive global markets.

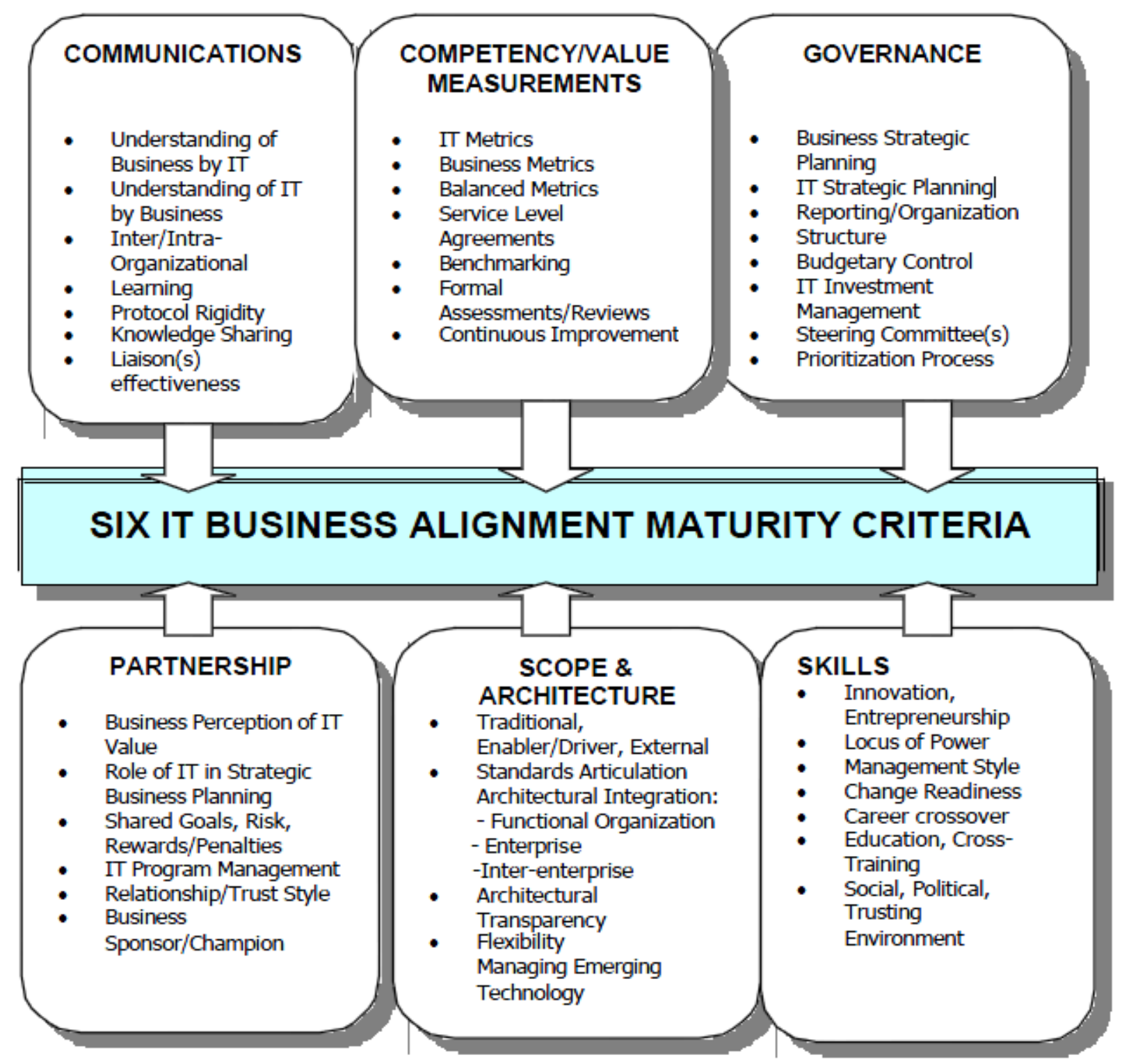

Figure 2. Alignment Maturity Criteria Modle (Luftman J. N 2000) 
In order to help customers learn to fully embrace the benefits of integrated Business Analysis/ Project Management/ HP has developed an integrated approach called Business Technology Optimization (BTO). With Business Technology Optimization, HP is helping customers use well-defined business requirements to drive IT in ways that achieve desired business outcomes. (Figure 3). Every business has specific, desired outcomes it wants to achieve. The business is starting from an existing state — the "as is" state — and wishes to move toward the desired outcomes - the "to be" state - based on its business strategy. The way to move from "as is" to "to be" is through successful implementation of programs and projects (in this case, IT solutions and services). The business defines programs and projects based on business requirements. It's the Business Analyst's role to (1) define the business requirements, and (2) ensure continuity throughout the project development so that the team doesn't lose sight of the original business requirements. The BTO framework is meant to keep IT focused on the desired business outcomes.

Outcomes are about more than just revenue growth and profitability. There are other dimensions to business outcomes achievable through IT. BTO is about. Three important business outcomes: Accelerating business growth, Lowering Cost and Mitigating.

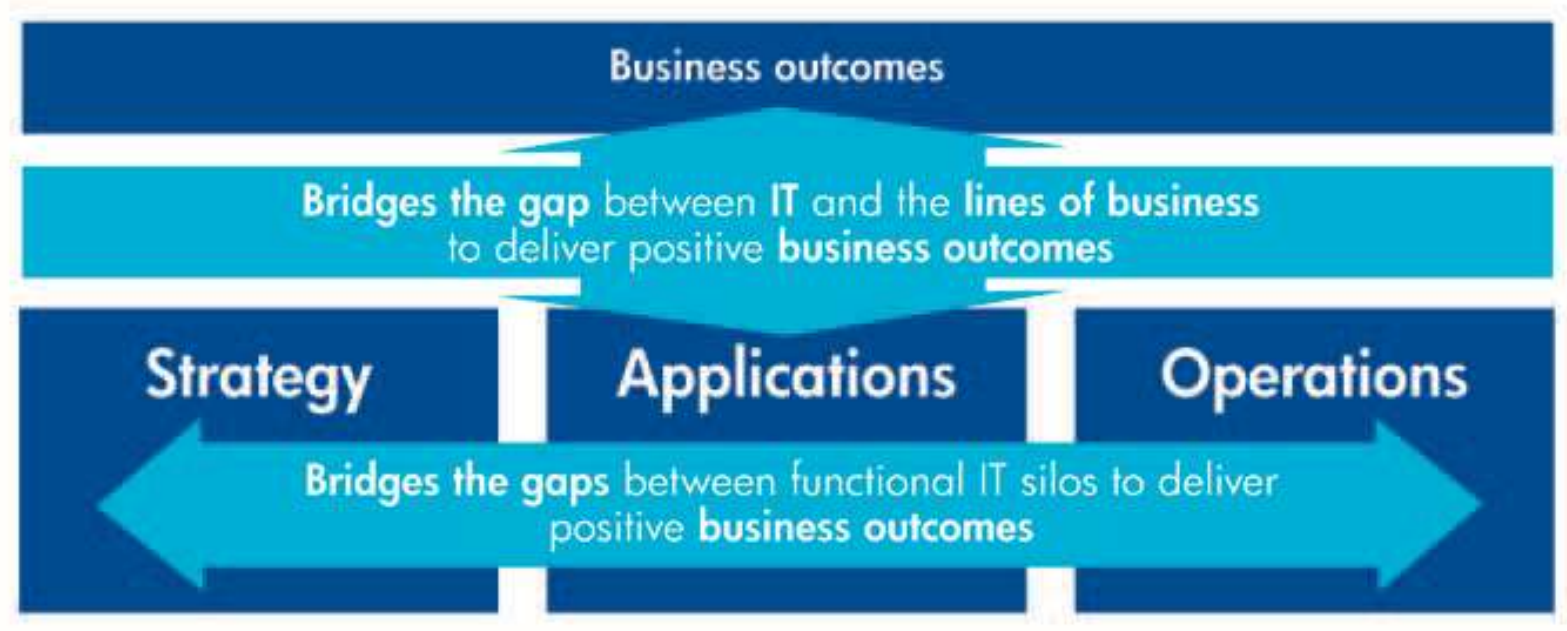

Figure 3. Business Technology Optimization Model (Bto) - (Hp Corporation 2010)

The DeLone and McLean (2002) Information Systems (IS) Success Model is a well-established model in the field of technology in general and information systems in particular. (Figure 4). This model offers the following hypothesis:

H1: Information Systems (IS) system quality, information quality and service quality will have a positive effect on the use of the system (and intention to use) as well as the user satisfaction of individual investors of online stock trading information systems.

H2: System use (and intention to use) as well as user satisfaction, are going to affect each other and will have a positive effect in introducing net benefits to the users of online stock trading information systems.

H3: The net benefits of online stock trading information systems are going to have a positive effect on system use (and intention to use) as well as the user satisfaction of individual stock investors. 


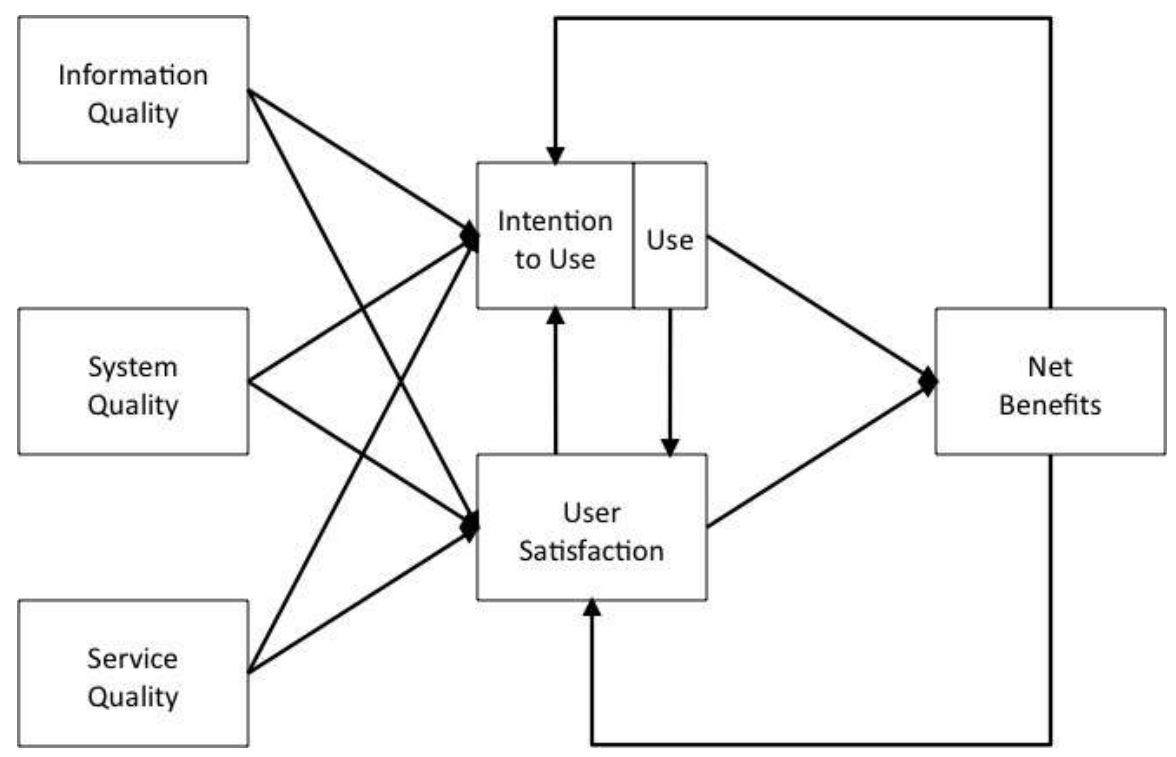

Figure 4. Information Systems Success Model (Mclean And Delone 2002)

After reviewing all the above models about alignment of IT with business objectives and integrating the well-established DeLone and McLean information systems success model, we introduce a new theoretical framework for IT/business alignment (Figure 5). This new model assumes that the organization's business infrastructure and IT infrastructure will affect each other and will affect the business strategy and the IT strategy. Both the business strategy and the IT strategy will affect the actual IT system implemented in the organization as well as the service quality of that system and the information quality produced by that system (which is the basis for decision making). System quality, information quality and service quality will affect the behavioral/intention to use the system as well as the user satisfaction with the system. These two will affect the actual use of the system, which will affect the net business benefits/objectives. Moderating factors of the Alignment Maturity Criteria Model of (Luftman J. N. 2000) above such as sills, communications, value measurements, governance, partnership, scope \& architecture and software applications will affect the system quality, service quality and information quality produced by the system. 


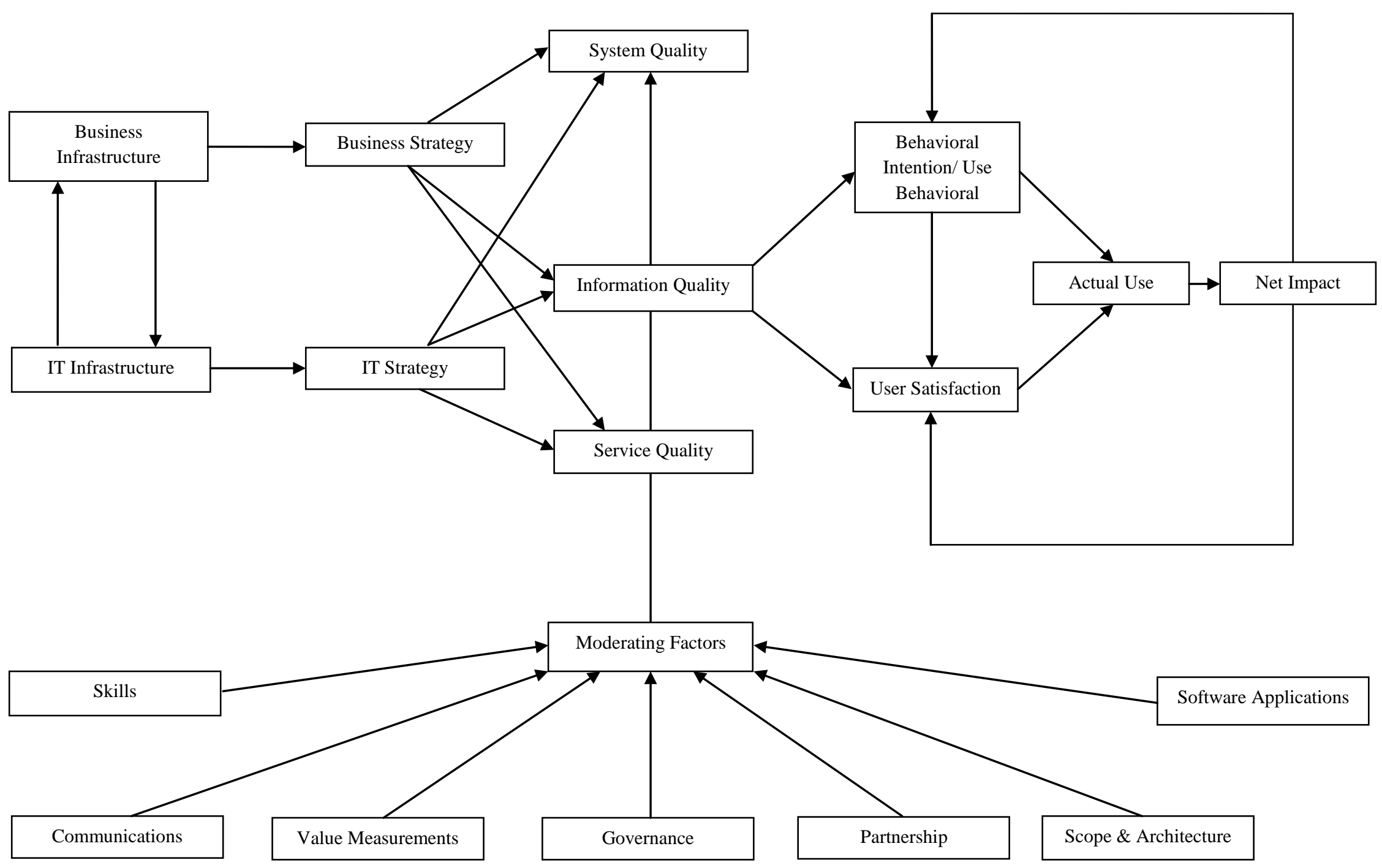

Figure 5. New Theoretical Framework For It/Business Alignment (Elmorshidy 2012) 


\section{CONCLUSION}

Business-IT strategic alignment is one of the most popular modern management concepts in business and IT management particularly in academia and industry. It refers to the degree of congruence between business and IT strategies. In today's turbulent and competitive business environment, survival not even success has become a major challenge. The basic foundation strategy that any type of business should have is to align Information Technology (IT) with business goals. The company should have clear business goals and employs its IT system to exactly achieve these goals. IT and IS are very important in the processes of business planning, design, analysis, operations management, and strategic decision making. Alignment is described as the appropriate and timely application of IT, in harmony with business objective, strategies, and requirements. Business and IT alignment occurs when the respective strategies are interwoven in such a way that the right things are done. Any business-IT alignment model or strategy must ultimately pursue one goal - continually optimize returns to the business from IT investments, including investments in projects, capital, service, support, maintenance, and any other IT effort or expenditure. The key success factor for aligning IT spending and efforts with business needs is mutual leadership and accountability. Regardless of its role, every IT activity, project, or service must play a part in creating business value. Also, an IT agenda must work must work towards achieving business-related and not IT-related metrics in order to improve alignment. Furthermore, businesses should be aware of their IT resources, which is something they often neglect to do. Fenwick (2012) advised to think beyond alignment and create a business strategy based on technology. In order to do that, he suggested a framework that involves several steps: 1. Tackle Goals And Objectives First, 2. Model Business Differentiators, 3. Feed Strategy Discussions With Data-Driven Insights, 4. Develop Multiple Business Technology Strategies, 5. Develop A Living Technology Road Map, 6. Create IT To Support The BT Strategic Plans.

The paper reviewed leading theoretical models about alignment of IT with business strategy including the strategic alignment model (Venkatraman et al. 1999), the Alignment Maturity Criteria Model (Luftman J. N 2000), the Business Technology Optimization Model (HP Corporation 2010). This paper also reviewed the 2002 McLean and DeLone Information Systems Success Model. After reviewing all the above models about alignment of IT with business objectives and integrating the well-established DeLone and McLean information systems success model, we introduced a new theoretical framework for IT/business alignment (Figure 5). This new model assumes that the organization's business infrastructure and IT infrastructure will affect each other and will affect the business strategy and the IT strategy. Both the business strategy and the IT strategy will affect the actual IT system implemented in the organization as well as the service quality of that system and the information quality produced by that system (which is the basis for decision making). System quality, information quality and service quality will affect the behavioral/intention to use the system as well as the user satisfaction with the system. These two will affect the actual use of the system, which will affect the net business benefits/objectives.

\section{AUTHOR INFORMATION}

Dr. Ahmed Elmorshidy is an assistant professor of Management Information Systems (MIS) and the Head of the Accounting and MIS department at Gulf University for Science and Technology in Kuwait. He received his Ph.D. in Management of Information Systems (MIS) in 2004 from Claremont Graduate University, Claremont, California, U.S.A. previously he has earned an MBA in 1995 and an M.A. in Computer Resources and Information Management in 1994 from Webster University, St. Louis, Missouri, U.S.A. Dr. Elmorshidy taught at several academic institutions including Alexandria University, Webster University, Claremont Graduate University, National University, and currently at Gulf University for Science and Technology in Kuwait. Dr. Elmorshidy's research interests are focused on online information systems and the effect of new and disruptive technologies on the field of MIS (Management of Information Systems). Dr. Elmorshidy is a member of IEEE organization and in the Association of Information Systems (AIS). E-mail: Morshidy.A@gust.edu.kw

\section{REFERENCES}

1. Baina, Salah, Ansias, Pierre-Yves, Petit Michaël, amd Castiaux, Annick ( 2008), "Strategic Business/IT Alignment using Goal Models", Proceedings of BUSITAL'08. 
2. DeLone, William H. and McLean, Ephraim R. (1992, March), "Information Systems Success: The Quest for the Dependent Variable", Information Systems Research. Pg. 60- 95.

3. DeLone, William H. and McLean, Ephraim R. (2002), "Information Systems Success Revisited", Proceedings of the $35^{\text {th }}$ Hawaiian International Conference on Systems Sciences (HICSS-35'02).

4. Dodani, Mahesh H. (2008), “Aligning IT to Business Through Architecture”, Journal Of Object Technology, Vol. 7, No. 6, July-August 2008.

5. Growthwave 2010, "Business-IT alignment: A model for success model", GrowthWave White Paper, www.growthwave.com

6. Haydamack, Craig and Johnson, Sarah (2008) Intel Corporation, “Aligning IT with Business Goals through Strategic Planning", White Paper, Intel Information Technology, December 2008.

7. Henderson, J., Venkatraman, N, "Strategic alignment: A model for organizational transformation through information technology. In model for organizational transformation through information technology. In T. Kochan, M.U., ed.: Transforming Organizations, Oxford University Press, NY. (1992)

8. HP Corporation (2010), "Optimizing IT to meet Business Objectives. The role of Business Analysis. Project Management and ITIL V3", HP Corporation Press 2010.

9. Infosys (2010), “Business and IT Alignment: Shall the Twain Ever Meet?”, Finical from Infosys 2010.

10. Lochan, Donie and Shah, Sachin (2010), "How to bridge the IT alignment gap?, Financial Times, Thursday, November 4, 2010.

11. Sarhandi, Muhammad Ilyas Jan, White, Beki Onome, Nadabo, Sulaiman, Ahmed, Syed Umer, Khan, Inam Ullah and Rasheed, Mohsin (2011),"Business-IT Alignment"'Stockholm University \& Royal Institute of Technology, Department of Computer and Systems Sciences 2011.

12. Strassmann, Paul A. (1989), "What is Alignment? Alignment is The Delivery of the Required Results" The Squandered Computer ,Cutter IT Journal, August 1998.

13. Fenwick, Nigel (2012), "Forget Alignment: How To Co-Create A Business Strategy", InformatioWeek, Global CEO, April 05, 2012 09:15 AM

14. Luftman, J. (1996,) "Competing in the Information Age: Practical Applications of the Strategic Alignment Model”, New York: Oxford University Press.

15. Luftman, J (2000), “Assessing Business-IT Alignment Maturity”, Communications of the Association of Information Systems, Volume 4, Article 14, 2000.

16. Luftman, J. and T. Brier (1999) "Achieving and Sustaining Business-IT Alignment," California Management Review, (42) 1, pp. 109-122.

17. Luftman, J., R. Kempaiah, and E. Nash (2005) "Key Issues for IT Executives", MIS Quarterly Executive (5) 2, pp. 81-101.

18. Luftman, J.N., Bullen, C.V., Liao,. D, Nash, E and Neumann, C. (2004), “Managing the Information Technology Resources: Leadership in the Information Age". Prince Hall, Inc. 


\section{NOTES}

